\title{
False messages in scientific publics using the example of Russian social network Vkontakte
}

\author{
Alexander Fedyukovsky ${ }^{1, *}$ \\ ${ }^{1}$ Peter the Great St. Petersburg Polytechnic University (SPbPU), Polytechnicheskaya str., 29, 195251, \\ St. Petersburg, Russia
}

\begin{abstract}
Information and communication technologies form, in different ways, the modern person's world picture. Despite huge educational possibilities of the Internet, the information flowing to the person through most commonly used channels, like social networks, can not be described as completely representing real facts. This problem is well considered in terms of policy, but the reliability or inaccuracy of the scientific information in social networks is studied little. This paper analyzes the degree of reliability of scientific facts contained in Russian social network VKontakte. The results show that more than half of messages (57\%) in publics called scientific do not contain scientific information, and $32.4 \%$ of the others contain not completely true information. The inaccuracy degree can vary considerably. It is possible to distinguish its following types: Inaccuracies, Exaggerations, Incomplete information, False attribution, Representing creative works as real, Gross errors in actual understanding. The analysis of false facts in scientific public shows that more often the facts are misrepresented to surprise, for the sake of this, numerical indicators are exaggerated, information partially disappears or misrepresented to look exclusive. There is an interesting trend of using "photoproofs" mismatching the text in time, place or general understanding, or just shots from films or works of art (in particular, digital art).
\end{abstract}

\section{Introduction}

The modern person does not think of himself or herself without information and communication technologies. They facilitate human life in various aspects. All information processes are accelerating, the quantity of information received by the person has grown at an exponential rate.

Easy information reception and distribution by means of information and communication technologies changes the shape of familiar social institutes. For example, elearning allows people to receive education in a convenient place and at a convenient time [1-6], introducing some child and youth-friendly elements, i.e., gamification [7] or virtual assistants [8], however, there appear some new problems connected both with the necessity to change the behavior model [9-11] and with imperfection of the system itself $[12,13]$.

\footnotetext{
* Corresponding author: fedyukovsky@mail.ru
} 
However, besides formal education or self-education, it is the Internet that becomes a global information-educational platform, a way of youth socialization. Reflection of various theories, processes and facts in the Internet influences the global scientific picture.

At the same time, there is quite low reliability of information, for example, in the social networks which are greatly popular among youth. Placing fake information is a known trend, and it often is investigated in the context of news reports, however, it is interesting to consider the information which can be qualified as vision of the world. The rational reasons of these fake news' occurrence can be found, for example, in the field of economic or political manipulations, e.g. to influence the outcomes of public events $[14,15]$, the consumer behavior strategy [16], etc., and are studied well enough today, but the distortion of vision of the world can hardly bring any obvious advantage to the author, except those cases when the scientific information is connected with important political and commercial interests.

The desire to share an obviously doubtful scientific fact, to forge proofs, or to make others believe false proofs of the scientific theory is not a new phenomenon. However, earlier the given phenomena belonged to the scientific community and, even leaving its frameworks, they were checked by scientific methods and, as a rule, were denied quickly enough.

The oldest case concerns the year of 1726, when Johann Beringer of Würzburg published in the book that he found some details of fossils (lizards in their skin, birds with beaks and eyes, spiders with their webs, and frogs copulating, Hebrew letters YHVH, for Jehovah, or God), considering them natural products of the "plastic power" of the inorganic world, that, as a result, appeared a sneer of the colleagues of that ill-fated author [17]. There were absolutely other motives of numerous authors showing "perpetuum mobiles", for example, in 1813 Charles Redheffer raised large sums of money, presenting a similar miracle-car, but was exposed by Robert Fulton, a mechanical engineer. Numerous pseudofossil ancient beings sometimes demanded more time for exposure, for example, Eoanthropus dawsoni, or Piltdown man, found in 1912, was defined as a crude forgery, the marriage of a modern human skull and an orangutan's jaw only in 1953 [17]. There are a number of known cases of publishing forged research results (e.g. on IQ heritability by Sir Cyril Burt, a professor of psychology at University College London, on advanced aspects of electronics by a young researcher at Bell Laboratories in New Jersey, Jan Henrik Schön, on discovering chemical elements 116 and 118 by Victor Ninov at Lawrence Berkeley National Laboratory in California).

Thus, the science institute possesses some internal mechanisms, fulfilled enough, for falsifications' retraction. However, the Internet mirror, where the science is reflected, is not just distorted, but it is more likely carnival. Social norms of behavior in the network are less strict $[18,19]$. So, an ordinary user of the network possesses limited possibilities for adequacy of information offered. Scheufele and Krause note that citizens are misinformed because they are unable to sift through and critically evaluate information in emerging (social) media environments [20].

\section{Methods}

In this research a set of theoretical and applied methods providing realization of analytical toolkit are used. Among them there are methods of complex and process comparative analysis and synthesis, grouping factual data, content analysis. In this research the interdisciplinary approach is used. It allows to estimate the conformity of the messages available in scientific groups of the Russian social network to the modern scientific knowledge, to distinguish principal views of errors and to reveal trends in communication sociology and science sociology. 
The qualitative and quantitative analyses are conducted. There were analyzed some dozens of groups (public pages) in VKontakte social network positioning as popular scientific resources, in total 1,500 messages, among which false ones were distinguished.

The analysis allowed to reveal the degree of mismatching the reality and the facts given in social networks, for that designing of logic schemes, graphic interpretation of theoretical information and empirical data were applied.

\section{Result and discussion}

It is necessary to note that the publics in VKontakte social network, positioning as "scientific" ones, actually contain a lot of information which has nothing to do with the science. There appears to be more than a half of messages $(57 \%)$ which does not contain any scientific information, most often these are beautiful images (of mountains, sea, urban architecture, animals), sometimes - videos of mostly comic content, "life hacks", etc.

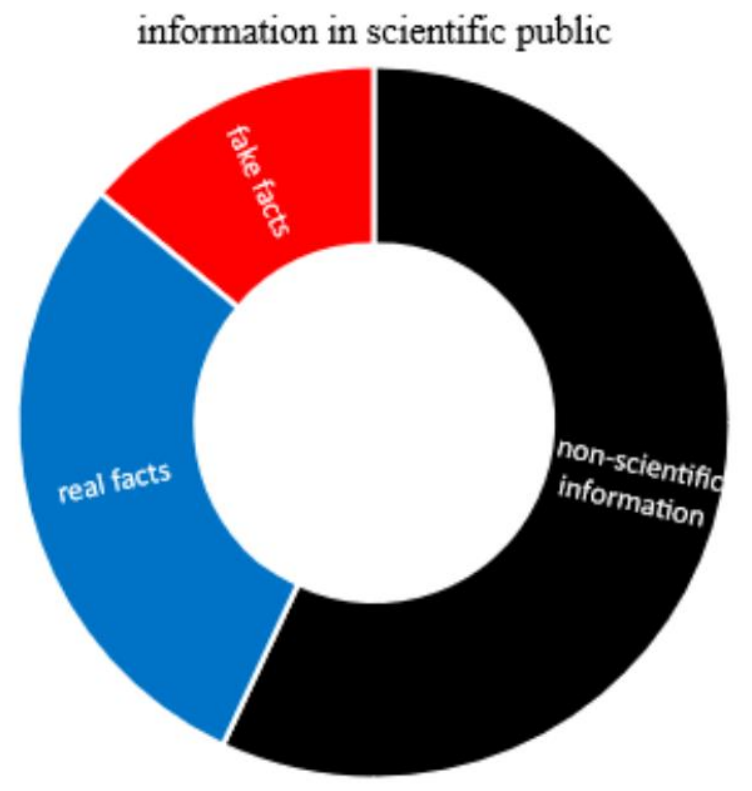

Fig. 1. The content of scientific publics in Russian social network VKontakte.

Popular scientific publics contain a very big percentage of misinformation however, the inaccuracy degree may be different (Fig. 2). In some cases it is an exaggeration (the length of tarantula, the biggest spider in the world, is $17.5 \mathrm{~cm}$; Snoring sound can reach 70 decibels, that is comparable to a jackhammer sound), an inaccurate formulation (The greatest desert on the Earth is the Sahara), providing incomplete information (The wolf is a unique animal which can fight against a stronger rival, Honey is a unique food which never spoils), some long known facts are presented as achievements (Modern planes are capable to overcome the sound velocity).

In other messages the information is an absolute lie and contains some rough factual errors (The weasel and ermine is the one animal changing the name with the wool color during the winter period; $300.000 \mathrm{~km}$ per second is the lightning speed; In addition to the fact that Baikal is the largest lake, it is also the deepest lake in the world). In this category there are some statements referring to researches available, but presenting some misunderstanding of scientific laws. For example, The Bumblebee is a biological paradox. After researching its aerodynamic qualities and the body weight, American scientists 
concluded that it cannot fly but it flies, appeals to the results of application to the bumblebee flight the same laws and formulae which are used in calculating the plane movement, that is, of course, wrong as the bumblebee flies in turbulent streams created by its wings' waves, and in calculating the plane flight it is enough to consider only the laminar air current.

If any discrepancy is thought to be a deceit, among the facts available in popular scientific publics, considered by us, there are, on average, $32.4 \%$ of false facts (fig. 1). Among the groups analyzed, the minimum truthfulness percent is 46 , and the maximum percent is 86 . The more the group is focused on entertaining content, the more unreliable information there will be. It is possible that truthful information is thought to be too boring, therefore the information on quantitative characteristics of many objects is exaggerated. In any way, the quantity of posts' likes and reposts does not correlate with the information reliability, false and true messages are equally attractive to subscribers.

Inaccuracies

\section{Exaggerations}

Incomplete

information

False attribution

Representing creative

works as real

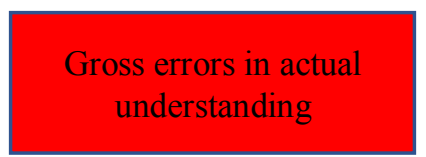

Fig. 2. Principal types of false scientific messages in the social network.

There is an interesting proportion of verbal and visual informations in posts. Most posts are accompanied by illustrations, which, in some cases, play the role of photoproofs (fig. 3). Sometimes it is a film shot, e.g. the message on a huge turtle found on the bank of the Amazon River is accompanied by the turtle photo, which size is more than a car carried by a lorry. Actually, that is an illustration - a shot from a science fiction film "Gamera the Brave". Sometimes, the information is true, but the photo is not, for example, to illustrate the message: The pink pigeon lives only in the south of Mauritius and eats only fruits and seeds, a very rare bird, on the verge of extinction they use not a bird described, but a painted domesticated pigeon. In general, animals are often identified incorrectly, less often there are problems with geographical objects.

Sometimes the message completely changes the sense of the illustration given, the text can distort the place, time and sense. Photos can be gathered from different unrelated posts. 
In a post, Devils Tower photo (a huge monolith of the volcanic origin) is represented as a tree stump: Here is a little stump remained of a tree on the territory of Wyoming, USA. The stump is $386 \mathrm{~m}$ high above the river valley. What the tree could look like in reality is shown in the picture. In another post, the cross-section cut of Ammophila arenaria leaf (where it is possible to see smiley faces) is called: The photo of a marihuana cell under the microscope. The stain on Jupiter, discovered in 1665, is interpreted as On Jupiter a huge cyclone has stormed for some weeks. It is the largest cyclone in the solar system which size exceeds our planet. Sometimes it can be just a vulgar interpretation of the image (i.e., Anthony Hearsey' photo - 3D-visualisation of the fire's origin points in Australia for a month - is signed as NASA shows Australia from space - all the continent is on fire).

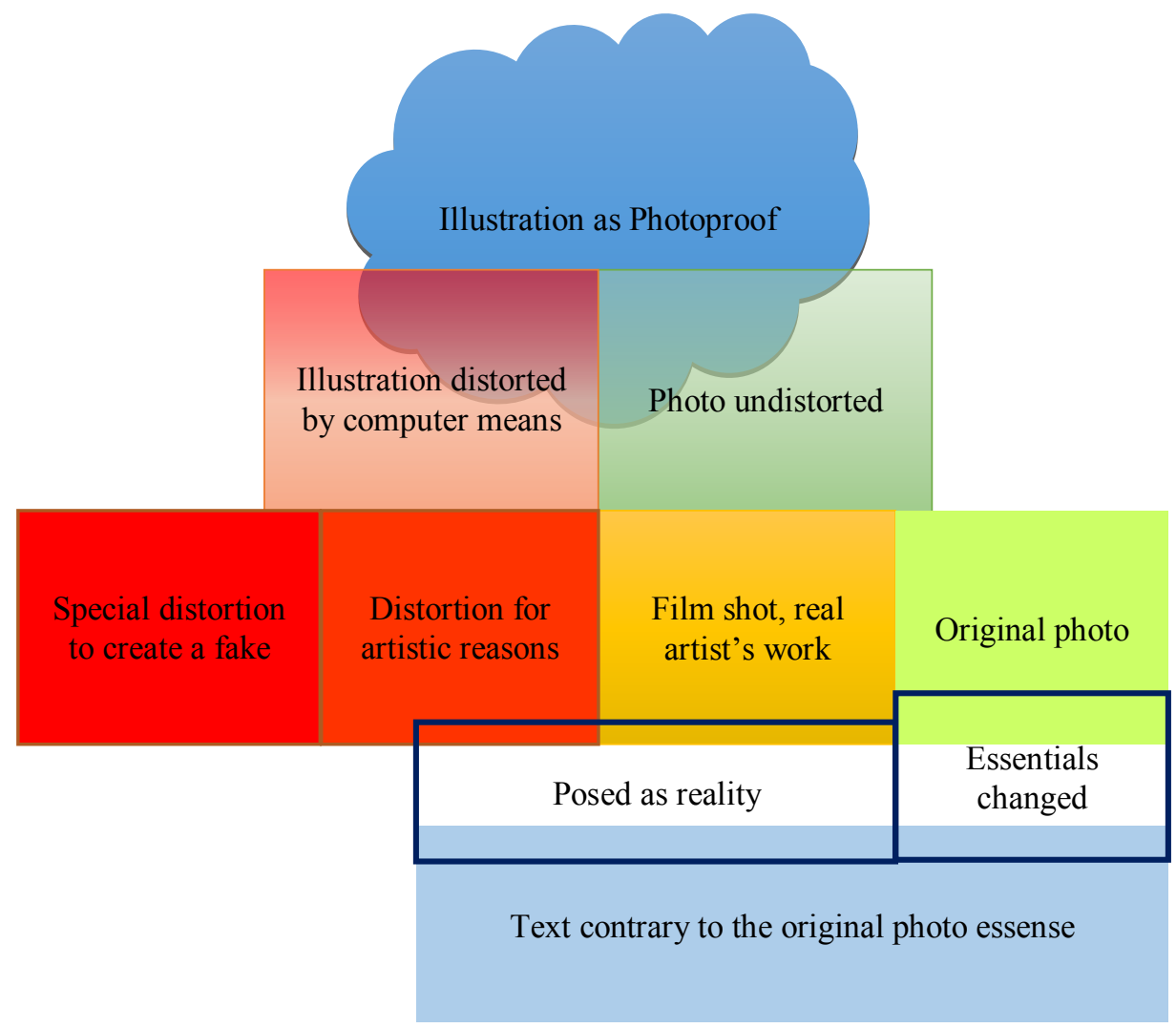

Fig. 3. The role of illustration in creating false scientific messages.

It is often in the photo where there is main information to shock and surprise viewers. The photo representing a dead snake with removed skin is accompanied by the inscription: It is both terrible and beautiful. The snake sheds its skin. Various creative works of artists, sculptors, puppeteers, computer graphic artists, etc., are often represented as real-life objects and living beings. Realistically made animals are often used to prove the existence of new species. Sometimes, these are just creative works, but sometimes they are photos of specially created fakes (e.g. Takeshi Yamada, a taxidermist, creates counterfeit beings from organic and inorganic materials). However, most often works of the artists transforming photomaterial with computer are represented as the truth. Merging the physical world reality and possibilities of its transformation in the Internet is an art trend today [21]. For example, the huge whale with its baby, floating under the bridge, a work by the digital artist Umut Reçber, is accompanied by the inscription: The picture is taken in Canada during 
moving of a giant whale with its baby under the Champlain bridge on the Ottawa river in Quebec), and works by the French artist and photographer Fabien Barrau, transforming natural outlines in recognized figures of animals are accompanied by the inscription: It is the nature which has worked here... It is delightful!

Not so often ( $4 \%$ ) there are also illustrations specially changed by means of computer processing images. The outlines of giant beings, as though photographed from the air (e.g. through the river water a huge snake is seen and signed Anaconda in the Amazon, a photo from the helicopter) are often shown. There are also classical Photoshop works, for example, the photoconnection of a monkey's muzzle with a hedgehog curtailing with its belly up is called Malagasy wood orangutan hedgehog.

The analysis of false facts in scientific public shows that more often the facts are distorted to surprise, for the sake of this, numerical indicators are exaggerated, information partially disappears or is distorted to look exclusive. The visual component of such messages is interesting. Sometimes it plays the role of proving the represented information, or even it informs the network users of the main idea. This phenomenon is especially interesting, as the computer space creates unlimited possibilities for visual distortion of reality. Today commercial media editing tools allow anyone to remove, add, or clone people and objects, to generate fake images [22], and developed means of identification of realistic fakes are not available for public.

The given research was spent only on materials of one Russian social network, further it is interesting to track how much the given tendencies extend worldwide and in different social networks and other Internet sources, and, also, how the false scientific information influences the network users' picture of the world. Researchers specify that exposing agents to the possibility of fake news can be an effective way to curtail the spread of fake news in social networks [23], there is a question, how much it is applicable to the scientific information. In general, when searching for misinformation, it is offered to rely on content based, source based or diffusion based [24].

Also, when analyzing fake news, it is noted that it is possible to relyo the users' reaction: i) for fake news, there is a sudden increase in the number of retweets and it does remains constant beyond a short time whereas in case of real news, there is steady increase in the number of retweets; ii) Fake news pieces tend to receive fewer replies than real news [25]. It would be interesting to track how important the given tendencies are for news messages. However, it is hardly possible to rely on the fact, that people, even considering "crowd wisdom", can be foretellers to define false messages, as researches specify that person has just a little better than a 50 percent chance of identifying misinformation [26], though defining the fakery of political news may be not a challenge, as Fake news in most cases is more similar to satire than to real news [27]. Available comments [28], context [29], and political and religious beliefs can also influence perception of the information accuracy [30].

\section{References}

1. N. Almazova, D. Bylieva, V. Lobatyuk, A. Rubtsova, in SPBPU IDE' 19 Proc. Peter Gt. St. Petersbg. Polytech. Univ. Int. Sci. Conf. Innov. Digit. Econ. (ACM, Saint Petersburg, 2019). DOI: 10.1145/1234567890

2. E. Razinkina, L. Pankova I. Trostinskaya, E. Pozdeeva, L. Evseeva, A. Tanova, E3S Web Conf. 110, 02097 (2019)

3. N. Almazova, D. Barinova, O. Ipatov, Ann. DAAAM Proc. Int. DAAAM Symp. 29(1), edited by B, 0587-0593 (Danube Adria Association for Automation and Manufacturing, DAAAM, Zadar; Croatia, 2018) 
4. N. Almazova, M. Kogan, Lect. Notes Comput. Sci. (Including Subser. Lect. Notes Artif. Intell. Lect. Notes Bioinformatics) 8524, 248-257 (Springer Verlag, 2014)

5. N. N. Pokrovskaia, M. Y. Ababkova, D.A. Fedorov, Educ. Sci. 9, 183 (2019)

6. A. Golikov, M. Kudaka, V. Sergeev, I. Sergeeva, P. Tishin, E. Tumakova, MATEC Web Conf. 193, 05059 (2018)

7. D.S. Bylieva, V.V Lobatyuk, T.A. Nam, IOP Conf. Ser. Earth Environ. Sci. 337, 012048 (2019)

8. D. Bylieva, N. Almazova, V. Lobatyuk, A. Rubtsova, Adv. Intell. Syst. Comput. 1114, 545-554 (2020)

9. D. Bylieva, V. Lobatyuk, A. Safonova, A. Rubtsova, Educ. Sci. 9, 167 (2019)

10. E. G. Pozdeeva, O. D. Shipunova, and L.I. Evseeva, in IOP Conf. Ser. Earth Environ. Sci. (2019), p. 012049

11. A. Rubtsova, IOP Conf. Ser. Mater. Sci. Eng. 497, 012059 (2019)

12. D.S. Bylieva V.V. Lobatyuk, T.A. Nam, Proc. 33rd Int. Bus. Inf. Manag. Assoc. Conf. IBIMA 2019 Educ. Excell. Innov. Manag. through Vis. 2020, 7469-7481 (2019)

13. D. Bylieva, V. Lobatyuk, S. Tolpygin, A. Rubtsova, Adv. Intell. Syst. Comput. WorldCIST' 20 (Springer, 2020)

14. N. Ruchansky, S. Seo, Y. Liu, Proc. 2017 ACM Conf. Inf. Knowl. Manag. - CIKM' 17, 797-806 (ACM Press, New York, New York, USA, 2017)

15. H. Allcott, M. Gentzkow, J. Econ. Perspect. 31, 211 (2017)

16. K. Shu, A. Sliva, S. Wang, J. Tang, H. Liu, ArXiv. Org (2017)

17. T. Radford, Guard (2003)

18. D. Bylieva, V. Lobatyuk, A. Safonova, Humanit. Soc. Sci. Rev. 7, 332 (2019)

19. D.S. Bylieva, V.V Lobatyuk, A.V Rubtsova, in IOP Conf. Ser. Earth Environ. Sci. Vol. 337 (2019), p. 012054

20. D.A. Scheufele, N. M. Krause, Proc. Natl. Acad. Sci. U. S. A. 116, 7662 (2019)

21. D. Bylieva, V. Lobatyuk, N. Ershova, Proc. Commun. Strateg. Inf. Soc. 18 (ACM, Saint - Petersburg, 2019). DOI: 10.1145/3373722.3373785

22. F. Marra, D. Gragnaniello, D. Cozzolino, L. Verdoliva, in 2018 IEEE Conf. Multimed. Inf. Process. Retr., 384-389 (2018)

23. C. Aymanns, J. Foerster, C.-P. Georg, ArXiv. Org (2017)

24. Á. Figueira, L. Oliveira, Procedia Comput. Sci. 121, 817 (2017)

25. J. Cao, Q. Sheng, P. Qi, L. Zhong, Y. Wang, X. Zhang, Arxiv. Org (2019)

26. J.M. Burkhardt, Libr. Technol. Rep. 53, (2017)

27. B.D. Horne, S. Adali, Elev. Int. AAAI Conf. Web Soc. Media (2017)

28. S.K. Yeo, L.Y.-F. Su, D.A. Scheufele, D. Brossard, M. A. Xenos, E.A. Corley, Information, Commun. Soc. 22, 129 (2019)

29. S.K. Yeo, M.A. Xenos, D.Brossard, and D.A. Scheufele, Ann. Am. Acad. Pol. Soc. Sci. 658, 172 (2015)

30. C. Drummond, B. Fischhoff, Proc. Natl. Acad. Sci. 114, 9587 (2017) 